\title{
Lower Lid Entropion Secondary to Missed Intraorbital Foreign Body in a Child
}

\author{
Othman Khairuddin"1,2, Abdul Rashid Suraida1,2, Li Min Evelyn Tai, ${ }^{1,2}$ Hussein Adil1,2, \\ Ahmad Tajudin Liza-Sharmini',2, Ibrahim Mohtar ${ }^{1,2}$
}

${ }^{1}$ Department of Ophthalmology, School of Medical Sciences, Universiti Sains Malaysia, Health Campus, Kubang Kerian, Malaysia

${ }^{2}$ Hospital Universiti Sains Malaysia, Kubang Kerian, Malaysia

Email: khairuddin_mdukm@yahoo.com, mohtar@usm.my

How to cite this paper: Khairuddin, O. Suraida, A.R., Evelyn Tai, L.M., Adil, H., Liza-Sharmini, A.T. and Mohtar, I. (2016) Lower Lid Entropion Secondary to Missed Intraorbital Foreign Body in a Child. Open Journal of Ophthalmology, 6, 198-204.

http://dx.doi.org/10.4236/ojoph.2016.64028

Received: September 5, 2016

Accepted: October 18, 2016

Published: October 21, 2016

Copyright $\odot 2016$ by authors and Scientific Research Publishing Inc. This work is licensed under the Creative Commons Attribution International

License (CC BY 4.0).

http://creativecommons.org/licenses/by/4.0/

\begin{abstract}
Background: Intraorbital foreign bodies can result in various complications if not appropriately managed. Aim: To report a case of lower lid entropion secondary to a missed intraorbital foreign body. Case Presentation: A 7-year-old boy presented with inward turning of the left lower lid for three days prior to admission. A week before, the child was in the garden when part of the roof of their home suddenly broke off, with pieces of the debris falling near him. He complained of left eye irritation, but a visit to a general practitioner found no eye abnormalities. Three days after that, the mother sought an ophthalmology opinion as she noticed inversion of the left lower lid. On examination, visual acuity in both eyes was $6 / 6$. There was left lower lid entropion, and a deeply embedded foreign body seen in the lower lid. No other eye abnormalities noted. Computed tomography scan of the orbits revealed a welldefined foreign object in the lower orbit, fracturing the antero-superior wall of the left maxillary sinus. The left eye foreign body was removed uneventfully via a transconjunctival approach. Conclusion: A thorough examination is mandatory in any case of ocular trauma especially in young children, who are usually unable to provide a clear history of the injury.
\end{abstract}

\section{Keywords}

Eye, Eye Injuries, Eye Foreign Bodies, Child, Entropion

\section{Introduction}

Children are particularly prone to orbital injury because the developing orbital bone offers little resistance. Foreign bodies most often encountered in the orbit are metallic objects and glass fragments [1] [2]. Ocular complications of intraorbital foreign body 
include optic nerve damage, extraocular muscle palsy secondary to direct muscle trauma or nerve damage, proptosis and orbital cellulitis [3]. It is uncommon for an orbital foreign body to present with isolated eyelid involvement. We report a rare presentation of an intraorbital foreign body presenting as a lower lid entropion in a 7-year-old boy.

\section{Case Report}

A 7-year-old boy presented to our eye clinic with a complaint of inward turning of the left lower lid for 3 days duration. According to the mother, the child was playing alone in the garden a week ago when part of the roof of their home suddenly broke off. She was alerted by the noise, and when she stepped into the garden, she noted a few bits of broken tiles on the ground. The child appeared to be unharmed, but complained of left eye irritation. She immediately brought him to a general practitioner, who reassured them that the patient had a normal eye examination. The left eye irritation resolved spontaneously, and the vision was good, with no double vision. However, after three days, the mother noticed that the left lower lid appeared to be inverted. When this did not resolve spontaneously, she brought her son to the ophthalmology clinic.

On examination, the visual acuity in both eyes was 6/6. Extraocular movements were full in both eyes, but there was pain in the left eye on upgaze position. There was a left lower lid entropion, and palpation of the left eye revealed a deeply embedded foreign body in the lower lid (Figure 1 \& Figure 2). The entropion was attributed to the mechanical effect of the foreign body. There were no signs of a conjunctival or corneal laceration wound (Figure 2). Both anterior segments and fundi were normal. The intraocular pressure was $14 \mathrm{mmHg}$ in both eyes.

Skull X-ray showed a left lower lid radio-opaque foreign body. Computed tomography (CT) scan of the orbits revealed a well-defined foreign object with sharp edges in the lower orbit (Figure 3 \& Figure 4). The object was projecting in an infero-oblique direction, fracturing and traversing the anterosuperior wall of the left maxillary sinus (Figure 4). It measured $1.4 \mathrm{~cm} \times 0.8 \mathrm{~cm}$ in size.

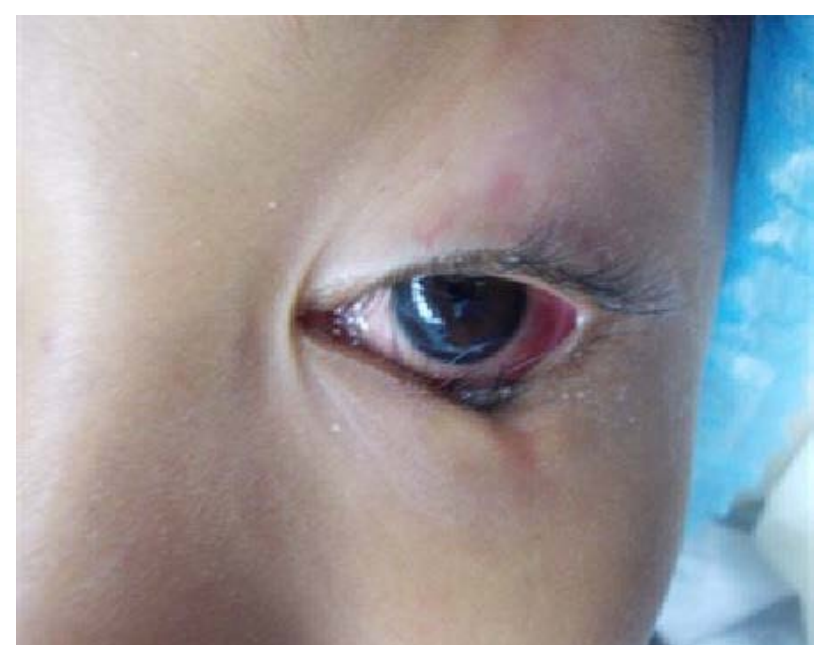

Figure 1. Left lower lid entropion on first presentation. 


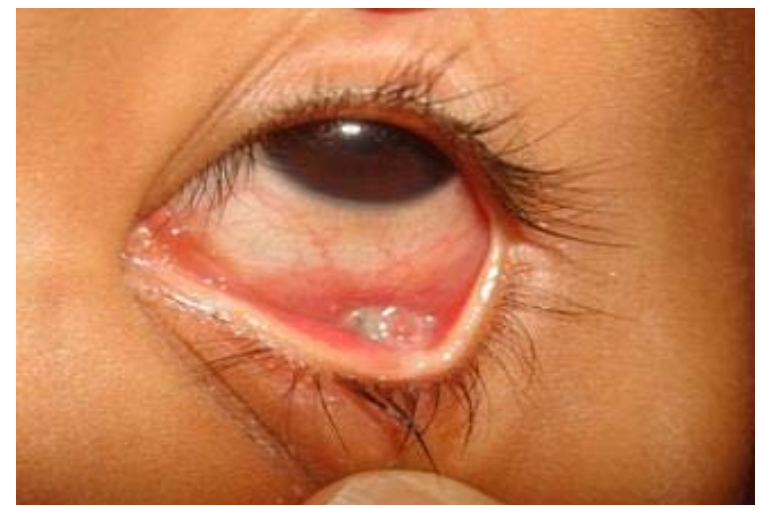

Figure 2. Foreign body seen in inferior fornix of left eye.

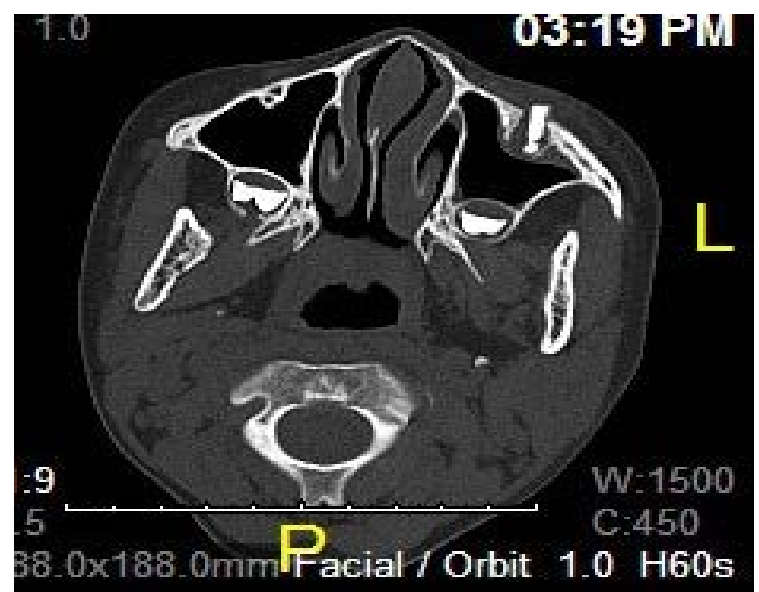

Figure 3. CT scan showing the foreign body in the left inferior orbital rim.

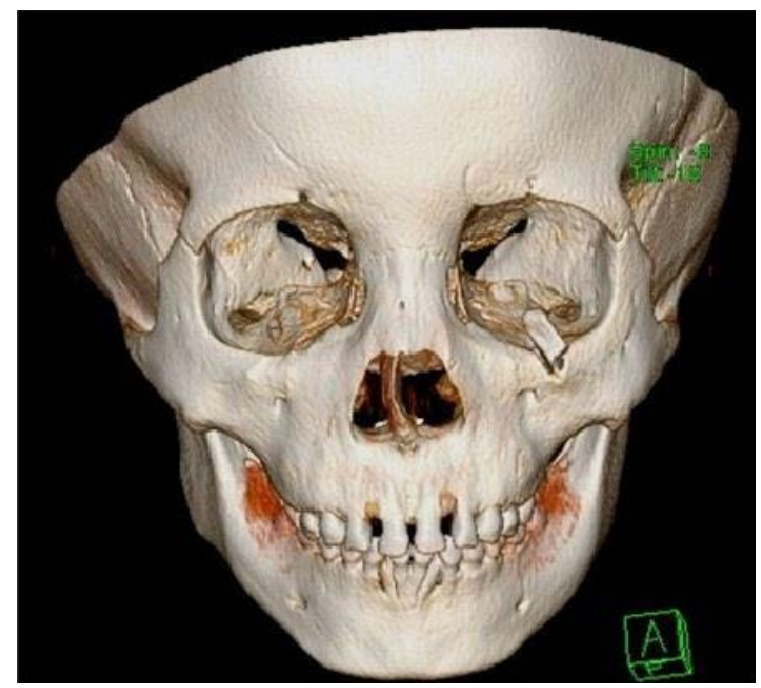

Figure 4. 3D bone reconstructed images showing the foreign body embedded in the left inferior orbital rim causing a fracture at the anterosuperior wall of the left maxillary sinus. 
The left eye foreign body was removed via a transconjunctival approach. The object was embedded in the inferior lower fornix, extending until the inferior orbital rim. It was identified as a stone, which was removed in one piece (Figure 5). It measured 1.3 $\mathrm{cm} \times 0.7 \mathrm{~cm}$. Granulation tissue was seen surrounding the bony defect and foreign body. The patient was assessed further by the oral-maxillary-facial team, who decided that no internal fixation was required for the inferior orbital rim fracture.

The patient was started on a five-day-course of intravenous amoxicillin clavulanate and metronidazole, which was continued orally for another week. Topical ceftazidime was also instilled 4 hourly. On post-operative day one, there was slight oedema of the left lower lid region, which resolved on subsequent follow-up. He was last seen 2 weeks post op and his wound had completely healed. He was planned for an entropion repair after 6 weeks.

\section{Discussion}

Intraorbital foreign bodies usually occur secondary to high velocity injuries, such as in gunshot or industrial accidents [2]. However, in cases where the trauma is deemed trivial, patients may not give a clear history of a penetrating injury. In this case, as the patient was playing unsupervised, the mother could not provide a clear history of trauma, and even the examination by a general medical practitioner failed to reveal the intraorbital foreign body. We postulate that the most likely mechanism of injury was that upon hearing the sound of the roof breaking, or perhaps alerted by bits of the falling debris, patient looked upwards, and a piece of the debris pierced the tarsal conjunctiva to bury itself in the inferior orbital rim.

Early clues giving rise to a clinical suspicion of an intraorbital foreign body include eyeball displacement, persistent inflammation and conjunctival chemosis. In cases where there is an associated fracture of the orbital floor, limitation of ocular movement with diplopia usually occurs, mainly due to inferior rectus entrapment and rarely, from nerve injury or muscle contusion [4]. In cases of retained organic foreign bodies, decay of the material over time with superimposed infection almost always results in abscess formation [5]. In cases where the foreign object is relatively inert, such as in this case,

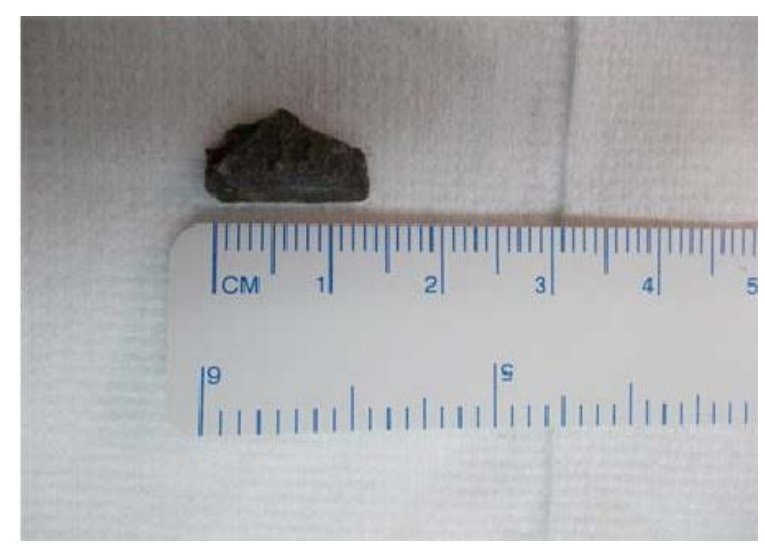

Figure 5. Foreign body identified as a stone. 
patients may be completely asymptomatic. It is likely that the initial discomfort experienced by the patient stemmed from the associated conjunctival wound. The latter was likely a self-sealing wound, which partially explains how the diagnosis was missed at the first presentation. A recent review highlights the importance of detailed examination of the conjunctiva and fornices as intraorbital foreign bodies usually penetrate the conjunctiva without causing eyelid laceration [6].

Imaging is invaluable in the evaluation of the globe and orbital integrity post trauma. Although X-ray is the initial imaging in cases of suspected intraorbital foreign bodies, computed tomography (CT) scan is the investigation of choice when there is a definitive history of penetrating injury, as even in cases of a radio-opaque object clearly visualised on X-ray, CT assists in planning of the surgical approach [2] [7]. It also enables to estimate the integrity of the orbital tissue and bone surrounding the foreign body.

The choice of imaging modality chiefly depends on the nature of the suspected foreign body. Plain film radiography is an economical method of visualising radio-opaque objects, but computed tomography still remains the gold standard of initial imaging [2]. However, in cases of organic foreign bodies, magnetic resonance imaging (MRI) may be required, as wooden objects tend to mimic air on standard CT window settings [8] [9].

Although complications associated with intra-orbital trauma include visual loss, orbital inflammation, secondary infection, osteomyelitis, ptosis and even brain abscess, in rare cases, no visual morbidity occurs [10]. In this case, although the foreign body was there for more than a week, the patient did not have any associated orbital cellulitis. This may be due to the inert nature of the foreign body, unlike in cases of intraorbital organic foreign bodies [11] [12]. Interestingly, the kind of injury sustained in this patient, i.e. a foreign body embedded in the inferior orbital rim and causing a fracture, is usually associated with high velocity injuries and thus greater visual disability [13]. Our patient was fortunate as his vision was still 6/6 in both eyes, and he did not develop any long term ocular complications.

Patients with suspected intraorbital foreign body are usually started on systemic antibiotics because of the high incidence of secondary orbital infections [2]. Anaerobic coverage should be provided where the foreign body is suspected to be composed of organic material [12]. Our patient was started on amoxicillin clavulanate for broad spectrum Gram-positive and Gram-negative coverage, and metronidazole for anaerobic coverage.

Management of the intraorbital foreign body depends on clinical presentation, nature and the location of the foreign body in the orbit. Because foreign bodies can cause irritation of the mucosa that can be result in sinusitis [4], the removal of all foreign bodies is generally recommended, even when they do not produce symptoms [14]. In rare cases, the foreign body may extrude spontaneously [12] [15], but in general, the decision of whether to remove an intraorbital foreign body has to be made by the co-managing team.

Presentation of the patient with visual compromise, ptosis, diplopia, orbital inflam- 
mation or infection mandates urgent removal. Likewise, surgical removal is indicated for all organic foreign bodies because of the high rate of secondary complications [2]. However, surgical exploration in case of inorganic foreign bodies depends on their location and the potential complications if left in place. For instance, the access to anteriorly located intraorbital foreign bodies is relatively simple, and thus these should be removed. In posteriorly located foreign bodies, however, the risk of surgery may outweigh the benefits, so in the absence of significant orbital complications, these should be left untouched [2].

\section{Conclusion}

Entropion is a rare presentation of an intraorbital foreign body. As intraorbital foreign bodies in children may not cause any significant symptoms, and history taking in this age group may be unreliable, the circumstances surrounding the injury should be examined closely. Care must be taken to correlate the history with a thorough clinical examination. A CT scan of the orbit is the imaging modality of choice for detection and localisation of a suspected foreign body. Early diagnosis and surgical exploration where indicated can prevent complications which may be sight threatening or even permanent disfigurement.

\section{Statement of Consent}

The patient and his guardian have given full consent for publication of this case report.

\section{References}

[1] Framme, C. and Roider, J. (1999) Epidemiology of Open Globe Injuries. Klinische Monatsblatter fur Augenheilkunde, 215, 287-293. http://dx.doi.org/10.1055/s-2008-1034716

[2] Fulcher, T.P., McNab, A.A. and Sullivan, T.J. (2002) Clinical Features and Management of Intraorbital Foreign Bodies. Ophthalmology, 109, 494-500. http://dx.doi.org/10.1016/S0161-6420(01)00982-4

[3] Simha, A., John, M., Albert, R.R. and Kuriakose, T. (2010) Orbito-Sinal Foreign Body. Indian Journal of Ophthalmology, 58, 530-532. http://dx.doi.org/10.4103/0301-4738.71710

[4] Sahin, Y.F., Muderris, T., Bercin, S., Sevil, E. and Kiris, M. (2012) Chronic Maxillary Sinusitis Associated with an Unusual Foreign Body: A Case Report. Case Reports in Otolaryngology, 2012, 903714. http://dx.doi.org/10.1155/2012/903714

[5] Tsaloumas, M.D., Potamitis, T. and Kritzinger, E.E. (1998) Two Cases of Retention of Wooden Foreign Bodies in Orbit of Eye. British Medical Journal, 316, 1363-1364. http://dx.doi.org/10.1136/bmj.316.7141.1363

[6] Shelsta, H.N., Bilyk, J.R., Rubin, P.A., Penne, R.B. and Carrasco, J.R. (2010) Wooden Intraorbital Foreign Body Injuries: Clinical Characteristics and Outcomes of 23 Patients. Ophthalmic Plastic and Reconstructive Surgery, 26, 238-244. http://dx.doi.org/10.1097/IOP.0b013e3181bd7509

[7] Arora, V., Kim, U.R., Shetty, S. and Shah, A.D. (2010) Atypical Presentation of an Unusual Foreign Body. Indian Journal of Ophthalmology, 58, 338-229.

http://dx.doi.org/10.4103/0301-4738.64138

[8] Ho, V.T., McGuckin Jr., J.F. and Smergel, E.M. (1996) Intraorbital Wooden Foreign Body: 
CT and MR Appearance. AJNR American Journal of Neuroradiology, 17, 134-136.

[9] Paul, A.M. and Grundmann, T. (2010) Intraorbital Wooden Foreign Body Undetected on CT. Indian Journal of Ophthalmology, 58, 1237-1240.

[10] Paya, C., Pinsard, L., Buestel, C., Bocquet, J., Delyfer, M.N. and Colin, J. (2010) Intraorbital Foreign Body. Journal Francais d Ophtalmologie, 33, 657.e1-657.e5.

[11] Karim, A., Taha, I., Tachfouti, S., Benzakour, H., Bencherif, Z., Cherkaoui, O., et al. (2006) Intraorbital Wood Foreign Body: A Case Study. Journal Francais d Ophtalmologie, 29, e29.

[12] Lakshmanan, A., Bala, S. and Belfer, K.F. (2008) Intraorbital Organic Foreign Body-A Diagnostic Challenge. International Journal of Ophthalmology, 27, 131-133.

[13] Czyz, C.N., Petrie, T.P., Harder, J.D., Cahill, K.V. and Foster, J.A. (2012) Intraorbital Foreign Body Projectile as a Consideration for Unilateral Pupillary Defect. International Journal of Emergency Medicine, 5, 14. http://dx.doi.org/10.1186/1865-1380-5-14

[14] Liston, P.N. and Walters, R.F. (2002) Foreign Bodies in the Maxillary Antrum: A Case Report. Australian Dental Journal, 47, 344-346. http://dx.doi.org/10.1111/j.1834-7819.2002.tb00549.x

[15] Banerjee, A., Das, A., Agarwal, P.K. and Banerjee, A.R. (2003) Late Spontaneous Extrusion of a Wooden Intraorbital Foreign Body. Indian Journal of Ophthalmology, 51, 83-84.

Submit or recommend next manuscript to SCIRP and we will provide best service for you:

Accepting pre-submission inquiries through Email, Facebook, LinkedIn, Twitter, etc.

A wide selection of journals (inclusive of 9 subjects, more than 200 journals)

Providing 24-hour high-quality service

User-friendly online submission system

Fair and swift peer-review system

Efficient typesetting and proofreading procedure

Display of the result of downloads and visits, as well as the number of cited articles

Maximum dissemination of your research work

Submit your manuscript at: http://papersubmission.scirp.org/

Or contact ojoph@scirp.org 